\title{
Costs of coexistence: understanding the drivers of tolerance towards Asian elephants Elephas maximus in rural Bangladesh
}

\author{
Omar Saif, Ruth Kansky, Anwar Palash, Martin Kidd and Andrew T. Knight
}

\begin{abstract}
Habitat degradation and fragmentation have heightened the importance of understanding human tolerance towards wildlife, as the fate of wildlife in multi-use landscapes depends on people's capacity for coexistence. We applied the wildlife tolerance model to examine drivers of tolerance towards Asian elephants Elephas maximus in rural Bangladesh, interviewing local people in 17 villages. We used structural equation modelling to identify causal pathways in which elephant-related exposure, positive and negative interactions, costs and benefits (tangible and intangible) contributed to tolerance. Contrary to expectations, monetary costs were non-significant in shaping tolerance despite major impacts on livelihoods. Instead, intangible costs and intangible benefits were significant factors determining tolerance. Furthermore, reducing people's exposure to elephants would not necessarily affect tolerance, nor would increasing positive interactions. We discuss how the socio-economic and bio-cultural dynamics of local communities can explain these results, and demonstrate how our model can be used to incorporate such complexities into conservation decision-making. For instance, compensation schemes aim to recompense monetary losses and direct damages, to improve tolerance, whereas our results suggest a more effective approach would be to enhance resilience to non-monetary costs and improve perceived benefits. We conclude that future studies should pay increased attention to intangible costs and consider the less direct drivers of tolerance. Through repeated testing of universal models such as that presented here, broad trends may emerge that will facilitate the application of policies across contexts and landscapes.
\end{abstract}

\footnotetext{
OMAR SAIF* (Corresponding author) and ANDREW T. KNIGHT† Department of Life Sciences, Imperial College London, Silwood Park Campus, Buckhurst Road, Ascot, Berkshire, SL5 7PY, UK. E-mail omarsaif.os@gmail.com

Ruth KansKY* Department of Conservation Ecology and Entomology, Stellenbosch University, South Africa

Anwar Palash Department of Zoology, University of Dhaka, Bangladesh

Martin Kidd Department of Statistics and Actuarial Sciences, Centre for Statistical Consultation, Stellenbosch University, South Africa

${ }^{*}$ Joint first authors

$\dagger$ Also at: ARC Centre of Excellence in Environmental Decisions, The University of Queensland, Australia, and Department of Botany, Nelson Mandela Metropolitan University, Port Elizabeth, South Africa

Received 5 February 2018. Revision requested 4 May 2018.

Accepted 8 August 2018. First published online 19 March 2019.
}

Keywords Bangladesh, conservation psychology, humanwildlife conflict, intangible costs, structural equation modelling, tangible costs, tolerance, wildlife tolerance model

Supplementary material for this article is available at https://doi.org/10.1017/Soo30605318001072

\section{Introduction}

A s human consumption and populations increase, the $\mathrm{A}_{\text {demand for land and natural resources inevitably }}$ intensifies pressure on wildlife, and this competition epitomizes the challenges associated with human-wildlife coexistence. Anthropogenic pressures are rapidly expanding globally, causing direct loss of biodiversity and a decline in human well-being (Dickman \& Hazzah, 2016). Multiple-use landscapes are often the most turbulent and complex contexts for securing coexistence, where managers are tasked with balancing multiple values and needs to ensure human well-being and secure conservation goals simultaneously (Peterson et al., 2013).

In such multi-use landscapes many large mammals with declining global populations occur outside protected areas (Di Marco et al., 2014), and their survival is dependent on human tolerance, which varies widely and is both multifaceted and complex (Treves \& Bruskotter, 2014). By understanding this diversity along with ecological thresholds, conservation managers will be able to identify how pressures on people and wildlife can be alleviated (Dickman, 2010).

Financial loss or infrastructure damage (tangible costs) are often presumed to be the primary determinants of tolerance (Barua et al., 2013). Accordingly, financial instruments such as compensation and crop/livestock insurance schemes are widely promoted by conservationists for (1) offsetting these tangible costs and (2) increasing tolerance (Dickman \& Hazzah, 2016; Ravenelle \& Nyhus, 2017). A typical example is compensation paid to the Mbirikani group in Kenya for livestock depredation, which reduced retaliatory killing of lions Panthera leo (Bulte \& Rondeau, 2007).

Although compensation schemes can be effective in ameliorating tangible costs (Ravenelle \& Nyhus, 2017), their effectiveness is increasingly questioned (NaughtonTreves et al., 2003; Marino et al., 2016); such schemes can have the unintended consequence of subsidizing agricultural expansion (Bulte \& Rondeau, 2005). Furthermore, communities may struggle to navigate bureaucratic systems 
for payment claims (DeMotts \& Hoon, 2012; Barua et al., 2013), payments are insufficient and often delayed (Ravenelle \& Nyhus, 2017), and societal rifts may develop when elite capture stymies the equitable distribution of funds (Sommerville et al., 2010).

Perhaps more fundamentally, compensation schemes may not lead to increased tolerance, a prerequisite for reducing human persecution of wildlife (Treves et al., 2009; Marino et al., 2016). For example, communities in Solapur, India, and Wisconsin, USA, neither reported nor expected payments to improve people's attitude towards wolves, despite the popularity of compensation in both locations (Agarwala et al., 2010). Compensation schemes may also have low effectiveness when intangible costs are more important than tangible costs for driving tolerance (DeMotts \& Hoon, 2012; Barua et al., 2013) but few empirical studies have examined this topic (Muradian et al., 2013). Kansky et al. (2016) found intangible rather than tangible costs, to be significant in driving attitudes towards chacma baboons Papio hamadryas ursinus in a South African urban context. Intangible costs are non-monetary, temporally delayed or psychological in nature (Ogra, 2008), typically embodied as fear, stress, sleep-deprivation or grief associated with the deaths of community members (Davies et al., 2011). These costs are difficult to assess (Schwerdtner \& Gruber, 2007), and with current policies and management focused on direct quantifiable damages (Ravenelle \& Nyhus, 2017) there is little impetus to address them (DeMotts \& Hoon, 2012). A review identified studies of 138 unique compensation programmes that ran during 1980-2015; within these studies there were 173 suggestions for improving compensation effectiveness, with only one identifying the need to account for psychological damages (Ravenelle \& Nyhus, 2017).

Here we quantify the drivers of tolerance towards Asian elephants Elephas maximus among subsistence rice farmers in Bangladesh. We define tolerance as the ability of the individual to absorb the potential or actual costs of living with wildlife (Kansky et al., 2016). Given the direct dependence of Bangladeshi communities on the natural resources they harvest, we test if tangible damage-related costs or intangible costs are more significant in driving tolerance. We apply the wildlife tolerance model (Fig. 1; Kansky et al., 2016) as the theoretical framework to uncover these pathways and indicate whether monetary compensation would be a useful intervention. We chose this particular model because (1) it distinguishes between tangible and intangible costs, (2) it comprises a set of indicators that are applicable for cross-cultural and cross-species comparisons, potentially providing landscape-level insights in the future (this is the second time this model is being applied), and (3) these variables are designed to be analysed using structural equation modelling, a statistically robust method for inferring causality in complex scenarios.



FIg. 1 The wildlife tolerance model (Kansky et al., 2016). In the outer model, tolerance is determined by the net perceived costs and benefits of living with a species, based on the extent to which a person experiences a species. The inner model consists of an additional 11 variables that influence tolerance through costs and benefits. The order of inner model variables listed in the inverted triangle is random. The triangle indicates that the 11 variables point to and drive tolerance through effecting perceptions of costs and benefits. ${ }^{*} \mathrm{PBC}$, perceived behavioural control.

\section{Study area}

The $180 \mathrm{~km}^{2}$ study area (Fig. 2) is in the Sherpur district of Bangladesh. It is an agricultural mosaic of paddy fields within a matrix of acacia Acacia catechu plantations and remnants of secondary Saal Shorea robusta forests (Islam et al., 2011). The site shares a national border and a transboundary elephant population of c. 50 individuals (Motaleb \& Ahmed, 2016) with the biodiverse Indian state of Meghalaya. Similar to Assam in India and south-east Bangladesh, northern Bangladesh has a history of difficult coexistence between people and elephants (Islam et al., 1999; Gogoi, 2018). Conflicts typically occur in paddy fields and households. During 2000-2018, 78 people died and 68 were injured by elephants in the study area, with c. $42 \%$ of fatalities reported in crop fields (as a result of crop-guarding) and c. $38 \%$ in homes (Aziz et al., 2016). Household destruction and agricultural losses were the most common types of damage reported, with villages closer to forests suffering more (Sarker \& Røskaft, 2014). Conflict is linked to degradation of the elephants' habitat as a result of unregulated firewood collection (residents have no other energy source for cooking), overgrazing and the clearing of remaining secondary forest for acacia plantations (Islam et al. 2011). It has been exacerbated by the expansion of the national border fencing, which has disrupted migrations and prevented herds from returning to the Meghalaya forests (Aziz et al., 2016), forcing them into closer proximity to people. Since 2008,25 elephant 


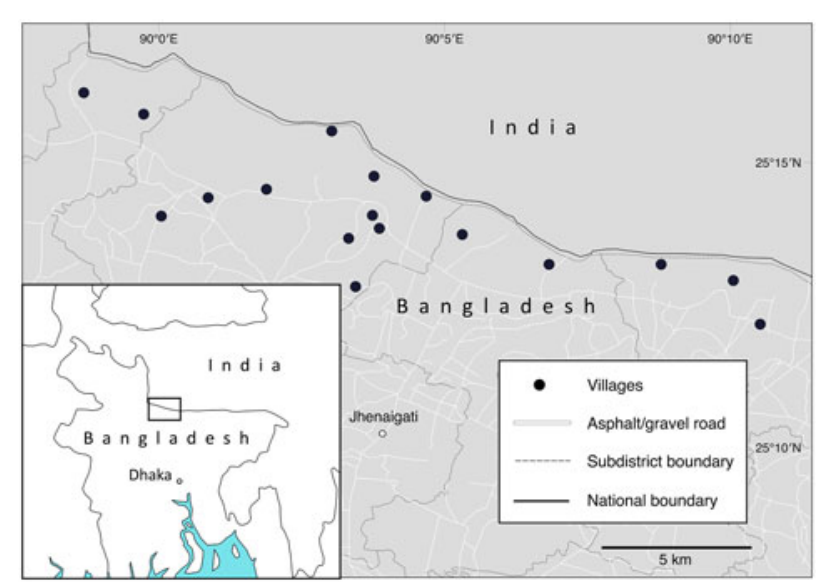

FIG. 2 Location of the study villages in Sherpur District, Bangladesh.

deaths have been recorded in the study area, with nine of those known to be caused by human intervention (Aziz et al., 2016).

\section{Methods}

The wildlife tolerance model consists of two components: an outer model with six variables and an inner model with 11 variables (Kansky et al., 2016). In the outer model, experience is the first variable and is operationalized using two variables: (1) recent exposure to a species, and (2) number of meaningful events a person has had with the species. Exposure measures the frequency and spatial proximity of a person's exposure to wildlife in a particular time frame. Meaningful events are emotionally charged experiences, which can be either positive or negative and are not time constrained; i.e. they could have occurred at any time in a person's life. Benefits and costs are the next pair of variables, and are separated into tangible and intangible. The first hypothesis of the outer model $\left(\mathrm{H}_{1}\right)$ is that experience drives perceptions of costs and benefits; if their experiences are more positive than negative, people will perceive greater benefits, and vice versa. The second hypothesis of the outer model $\left(\mathrm{H}_{2}\right)$ is that cost and benefit perceptions drive tolerance.

The inner model consists of 11 variables predicted to influence perceptions of costs and benefits: wildlife value orientation, anthropomorphism, interest in animals, taxonomic group, personal norm, institutions, empathy, values, norms, habits, and perceived behavioural control. For example, people who are more interested in animals are hypothesized to perceive relatively more benefits than costs, and therefore to be more tolerant than those who dislike animals. The outer and inner models can be applied independently or together, depending on the context and resources available. If the community in question is not in direct contact with wildlife (e.g. when determining how tolerant UK citizens would be towards the reintroduction of the lynx
Lynx $\operatorname{lyn} x)$ then only the inner model variables are applicable, as there is no experience with the species. In this study we tested the two hypotheses of the outer model only. The variables are described in Table 1.

We conducted pilot interviews $(n=37)$ in villages with a history of human-elephant conflict. We evaluated the results and made changes to the survey instrument to align with the socio-cultural context of Bangladeshi farmers. The final survey of 243 households was conducted during May-July 2016 in 17 villages. We interviewed male heads of households from the major cultural groups (BengaliMuslims, 63.94\%; Garo-Christians, 19.74\%; Koch-Hindus, $16.32 \%)$, typical of the overall population in the northern extents of Sherpur District. We interviewed men exclusively because during the pilot study women were unable to answer questions relating to tangible costs (e.g. the financial damage to crops), meaningful events, and exposure (e.g. number of elephant visits to farms), which are necessary to build the outer model. Two Bangla-speaking interviewers administered randomized household interviews (Babbie, 2015). Whilst walking in one direction through a village, each household was approached for availability for an interview. The ethnicity/religion of the occupier was not known prior to conducting the interview, and the number of householders interviewed in each village varied. Respondents were asked to participate in a rural livelihood survey (Supplementary Table 1); elephants were not mentioned explicitly, to avoid response bias.

We analysed the survey results using partial least squares structural equation modelling (Hair et al., 2016), to test relationships between the outer model variables, using SmartPLS (Ringle et al., 2015). Partial least squares is a less frequently applied structural equation modelling method that is preferred when conducting exploratory theoretical research, compared to the more typical covariate-based methods, which are usually used to accept or reject more established hypotheses (Reinartz et al., 2009; Lowry \& Gaskin, 2014).

Structural equation modelling consists of (1) a measurement model, which assesses how distinct constructs are from each other based on the indicators used (Lowry \& Gaskin, 2014), and (2) a structural model, which evaluates the relationships between independent and dependent latent variables (latent variables are abstract complex phenomena that are not directly observable). Interviews with $>30 \%$ missing responses were removed from the dataset to ensure the overall model's predictive reliability.

We evaluated the measurement model across five models to ensure reliability: the full model, and four models with systematic removal of indicators from constructs. These were assessed by calculating (1) indicator reliability, which represents how much of the variation in an indicator is explained by the variable, (2) discriminant validity, which indicates the extent to which a variable is truly distinct from other 
TABLE 1 Descriptions of the outer model variables of the wildlife tolerance model that were applied in a survey to investigate tolerance of Asian elephants Elephas maximus in rural Bangladesh, with examples of survey questions. The full set of questions and measurements is in Supplementary Table 1.

\begin{tabular}{|c|c|c|}
\hline $\begin{array}{l}\text { Outer model } \\
\text { variables }\end{array}$ & Description & Sample question from the survey instrument \\
\hline Tangible costs & $\begin{array}{l}\text { Direct costs incurred from living with wildlife, such } \\
\text { as monetary loss through crop \& household damage, } \\
\text { labour costs, time lost, injuries \& fatalities }\end{array}$ & $\begin{array}{l}\text { How much damage did elephants cause to your prop- } \\
\text { erty in the last wet season \& winter? }\end{array}$ \\
\hline Intangible costs & $\begin{array}{l}\text { Non-monetary costs such as stress \& fear resulting } \\
\text { from direct \& indirect interactions with wildlife }\end{array}$ & $\begin{array}{l}\text { What emotions do you feel living with elephants in } \\
\text { your area? Please tick as many feelings as necessary \& } \\
\text { indicate the intensity of the feeling on a scale of } 0-3 \text { : } \\
\text { frightened, wary, nervous, furious, frustrated, animos- } \\
\text { ity, miserable, unsettled }\end{array}$ \\
\hline $\begin{array}{l}\text { Tangible } \\
\text { benefits }^{1}\end{array}$ & $\begin{array}{l}\text { Compensation or equipment provided by NGOs/gov- } \\
\text { ernments to mitigate damage; the development of } \\
\text { social institutions such as schools }\end{array}$ & $\begin{array}{l}\text { Have you ever received any benefits from living with } \\
\text { elephants; e.g. from development programmes, NGO } \\
\text { compensation or subsidies for crops? }\end{array}$ \\
\hline $\begin{array}{r}\text { Intangible } \\
\text { benefits }\end{array}$ & $\begin{array}{l}\text { Non-monetary benefits related to the existence of a spe- } \\
\text { cies for the individual, the community, mankind \& nature }\end{array}$ & $\begin{array}{l}\text { Please indicate how beneficial or not you think } \\
\text { elephants are for your community. If you think there } \\
\text { are any benefits, please list them. }\end{array}$ \\
\hline Exposure & $\begin{array}{l}\text { Refers to the frequency \& spatial proximity of an } \\
\text { individual interacting with a species }\end{array}$ & $\begin{array}{l}\text { How many times did you see elephants on your farm/ } \\
\text { land in the last dry season? }\end{array}$ \\
\hline $\begin{array}{l}\text { Negative meaningful } \\
\text { events }\end{array}$ & $\begin{array}{l}\text { Negative emotionally charged experiences that may } \\
\text { have occurred at any time during an individual's lifetime, } \\
\text { such as wildlife causing the death of a family member }\end{array}$ & $\begin{array}{l}\text { Have you had any particularly negative, traumatic or } \\
\text { scary experiences with elephants? }\end{array}$ \\
\hline $\begin{array}{l}\text { Positive meaningful } \\
\text { events }\end{array}$ & $\begin{array}{l}\text { Positive emotionally charged experiences that may have } \\
\text { occurred at any time during an individual's lifetime, such } \\
\text { as an unforgettable meaningful experience with wildlife }\end{array}$ & $\begin{array}{l}\text { Have you had any particularly positive experiences } \\
\text { with elephants? }\end{array}$ \\
\hline Tolerance & $\begin{array}{l}\text { Measured through four main parameters: (1) tolerance } \\
\text { towards the killing of problem species under various } \\
\text { contexts, (2) the population size of a species a person is } \\
\text { willing to accept (Kansky et al., 2016), (3) tolerance } \\
\text { towards elephants visiting the village, on a scale from } \\
\text { never to numerous times per week, (4) tolerance } \\
\text { towards various levels of crop damage }\end{array}$ & $\begin{array}{l}\text { Would you like the population of elephants in your area } \\
\text { to decrease, stay the same or increase? }\end{array}$ \\
\hline
\end{tabular}

${ }^{1}$ Tangible benefits were not included in the analysis because of insufficient numbers of responses.

variables thereby capturing phenomena not represented by other constructs in the model, (3) composite reliability, which shows whether the indicators measuring a variable are similar in their scores, and (4) convergent validity, which shows whether variables that should be theoretically related to each other are observed to be so, and is measured through the average variance extracted (Hair et al., 2016).

The structural model utilizes the set of indicators collected via the survey (Supplementary Table 1) to create the latent variables, also known as constructs. The importance of (i.e. variance explained by) each construct is computed by $R^{2}$, the coefficient of determination, and the relationships between each construct by the path coefficient (Hair et al., 2016; Fig. 3). The path coefficients describe the extent to which each construct affects the other $(-1$ indicates a highly negative impact and +1 a highly positive impact). The relative statistical importance of the path coefficients is determined using their varying weights, and facilitates ranking (Wong, 2013). We calculated bootstrap confidence intervals and evaluated the significance of path coefficients by ascertaining if zero falls within the $95 \%$ confidence intervals (Hair et al., 2016).

\section{Results}

Of the 243 interviews conducted, 234 were used in the analysis. Descriptive results for the outer model constructs are presented in Table 2, and indicate the experiences, costs, benefits and tolerance experienced by the population. We found no differences in tolerance by age or religious affiliation (Supplementary Material 2). Tangible benefits were not analysed, as respondents failed to deliver sufficient responses for structural equation modelling.

The results for measurement models 1-5 are presented in Table 3. Low convergent validity resulted for tangible costs (0.25) and intangible benefits (0.35) when all indicator items were used in the analysis (i.e. model 5). This had little impact on composite reliability, path coefficients and $R^{2}$ values (Tables 3, 4 \& 5, respectively). In addition, indicator reliability, measured as outer loadings (Supplementary 


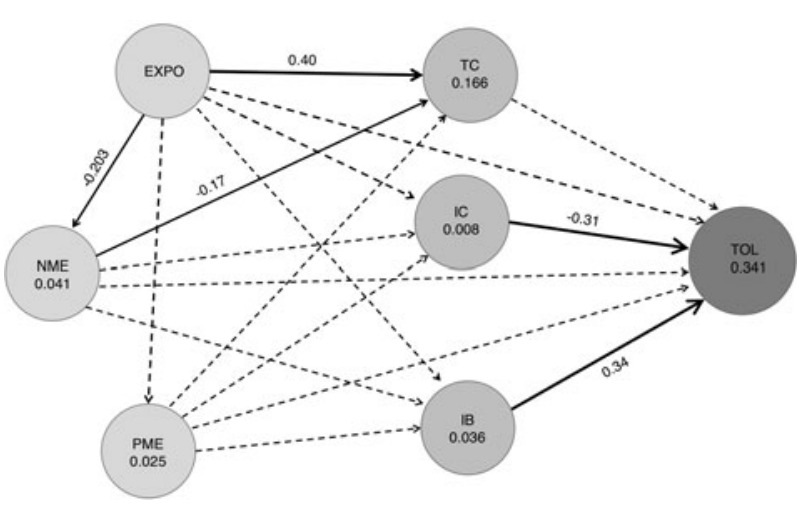

FIG. 3 Partial least squares structural equation models of latent variables: tangible costs (TC), intangible costs (IC), intangible benefits (IB), exposure (EXPO), negative meaningful events (NME), positive meaningful events (PME), and tolerance (TOL). Values within the circles are the coefficients of determination $\left(R^{2}\right)$. Lines joining circles are the path coefficients linking the latent variables. Solid lines represent significant path coefficients and dashed lines non-significant path coefficients.

Table 2), showed consistent results across variations of the model. We report model 3 (Fig. 3) but the other models yielded similar conclusions. The discriminant validity for the Fornell-Larckner criterion was not met for two pathways for intangible benefits and tangible costs, which is probably related to their low convergent validity ( 0.44 and 0.51 , respectively) but there was discriminant validity for these pathways in our other models ( 1 and 5 ), which suggests these constructs are distinct. As the wildlife tolerance model is still an exploratory model, further work will be required to improve on the low convergent validity and discriminant validity measures under various contexts (Ping, 2007).

Results from our structural model (Fig. 3) indicate that of the experience constructs (exposure, negative and positive meaningful events) only exposure (o.40) and negative meaningful events $(-0.17)$ drove tangible costs, whereas their effect on intangible costs and benefits were nonsignificant (Table 4). Approximately $17 \%$ of variation in tangible costs was explained by exposure and positive meaningful events, and $2 \%$ of variation in intangible benefits and o\% in intangible costs were explained by the three experience constructs (Table 5).

Regarding our second hypothesis, we found that intangible costs ( -0.31$)$ and benefits (o.34) significantly drove tolerance, yet tangible costs were non-significant (Table 4). Approximately $34 \%$ of variance in tolerance was explained by tangible costs, intangible costs and intangible benefits.

\section{Discussion}

Considering the direct reliance of rural Bangladeshi communities on the crops they harvest for personal consumption, it could be assumed that their tolerance for wildlife would be determined by the level of threat posed to their livelihoods. Our results indicate that communities suffer considerable monetary losses from damage caused by elephants $(15.5 \%$ mean loss of annual income). However, those experiencing higher monetary losses were not necessarily less tolerant, as indicated by the non-significant path coefficient between tangible costs and tolerance. In a previous study using the wildlife tolerance model in Cape Town, South Africa, tangible costs were also non-significant in driving the tolerance of urban residents towards baboons Papio spp. (Kansky et al., 2016). In the South African study this was perhaps unsurprising given that the livelihoods of relatively well-off urban residents were not particularly affected by baboon damage (Kansky et al., 2016). However, in our study these results are more surprising given the reliance of farmers on rice as a staple food.

Within the complexity of a multi-use landscape such as that in our case study, multiple safety nets may reduce the impact of financial damages and costs (Aziz et al., 2016). Close family units often provide resilience against wildlife damage by covering each other's crop losses and providing emotional coping mechanisms (DeMotts \& Hoon, 2012; Gogoi, 2018). In addition, diversification of incomes from casual labour (e.g. logging in our study) reduces dependence on agricultural production to maintain livelihoods. Such existing mechanisms that mitigate the negative impacts of wildlife should be identified before implementing new conservation initiatives, and fostered thereafter. It should also be noted that agrarian communities may have been led unwittingly to partake in forest-degrading livelihood activities (e.g. logging) with the promise of economic gains, which may ultimately lead to negative livelihood impacts.

In synergy with these socio-economic safety nets, a spiritual belief common across the three main cultural groups in Sherpur is that damage by wildlife is God's will (Inskip et al., 2016), which may explain the lack of significant relationships between tangible costs and tolerance. For example, one respondent stated:

If I have the blessing of God, elephants will not create any trouble in the locality, even to our crops.

Another, whose child had been killed by a raiding elephant, stated:

My child's lifetime expired and that's why he was killed. There is no way to blame the elephant.

\section{A third stated:}

If a child drowns you don't blame or hurt the water so how could you want to hurt an elephant if it was the reason the child died?

Similar beliefs have been recorded in other cases; e.g. regarding Bengal tigers Panthera tigris tigris in the Bangladeshi Sundarbans (Inskip et al., 2016) and elephants in Assam, India (Gogoi, 2018). This fatalistic acceptance of severe losses appears to be founded upon a belief that wildlife 
TABLE 2 Observed indicators from the wildlife tolerance model's outer constructs. For a description of indicator calculations that determine the construction of latent variables see Supplementary Table 1.

\begin{tabular}{|c|c|c|}
\hline Observed indicators & Mean \pm SD & Measurement scale \\
\hline \multicolumn{3}{|l|}{ Exposure } \\
\hline Elephants seen in the area (dry season) & $3.27 \pm 1.45$ & $0-7(0=$ never; $7=$ weekly $)$ \\
\hline Elephants seen in the area (wet season) & $3.27 \pm 1.58$ & $0-7(0=$ never; 7 = weekly $)$ \\
\hline Elephants seen on the farm (dry season) & $4.57 \pm 2.78$ & $0-7(0=$ never; $7=$ weekly $)$ \\
\hline Elephants seen on the farm (wet season) & $6.01 \pm 1.22$ & $0-7(0=$ never; $7=$ weekly $)$ \\
\hline Positive meaningful events & $4.25 \pm 3.21$ & Mean number of experiences during a lifetime \\
\hline Negative meaningful events & $1.60 \pm 2.23$ & Mean number of experiences during a lifetime \\
\hline \multicolumn{3}{|l|}{ Tangible costs } \\
\hline Mitigation efforts & $3.72 \pm 0.98$ & $\begin{array}{l}\text { Mean number of mitigation efforts used } \\
\text { (out of } 7 \text { ) }\end{array}$ \\
\hline Damage to household in dry season (6 months) & USD $110.5 \pm 16,110.70$ & Mean cost per dry season \\
\hline Damage to household in wet season (6 months) & USD $41.01 \pm 6,263.10$ & Mean cost per dry season \\
\hline Spent on mitigation measures (total per year) & USD $62.03 \pm 4,422.56$ & Mean cost per dry season \\
\hline Time spent guarding against elephants & $3.44 \pm 7.45$ & $\begin{array}{l}\text { Number of hours per day during harvest } \\
\text { seasons }\end{array}$ \\
\hline \multicolumn{3}{|l|}{ Intangible costs } \\
\hline Negative emotions felt living with elephants & $2.06 \pm 2.23$ & $0-3(0=$ none; $3=$ strong $)$ \\
\hline Extent of danger posed by elephants to people & $4.88 \pm 0.49$ & $0-5(1=$ none; $5=$ strong $)$ \\
\hline Extent of your fear of elephants & $3.73 \pm 1.60$ & $0-5$ ( $1=$ none; $5=$ strong $)$ \\
\hline $\begin{array}{l}\text { Extent of your fear for the lives of household members } \\
\text { as a result of living with elephants }\end{array}$ & $4.51 \pm 0.97$ & $0-5(1=$ none; $5=$ strong $)$ \\
\hline Opportunity costs from living with elephants & $4.59 \pm 0.64$ & $\begin{array}{l}\text { This is the mean of the five intangible cost } \\
\text { indicators below }\end{array}$ \\
\hline Extent of fatigue from guarding crops & $4.66 \pm 0.78$ & $0-5(1=$ none; $5=$ strong $)$ \\
\hline Extent of worry for safety of children & $4.82 \pm 0.64$ & $0-5(1=$ none; $5=$ strong $)$ \\
\hline Extent of vigilance towards elephants & $3.98 \pm 1.26$ & $0-5(1=$ none; $5=$ strong $)$ \\
\hline Extent of time spent dealing with elephants & $4.60 \pm 0.78$ & $0-5(1=$ none; $5=$ strong $)$ \\
\hline Extent your wife fears for your life whilst guarding & $4.87 \pm 0.50$ & $0-5$ ( 1 = none; $5=$ strong $)$ \\
\hline \multicolumn{3}{|l|}{ Intangible benefits } \\
\hline Positive emotions felt living with elephants & $1.86 \pm 0.49$ & $0-3(0=$ none $; 3=$ strong $)$ \\
\hline Extent of benefits from elephants to yourself & $1.38 \pm 0.63$ & $1-5(1=$ none; $5=$ very beneficial $)$ \\
\hline Extent of benefits from elephants to your community & $1.14 \pm 1.16$ & $1-5(1=$ none; $5=$ very beneficial $)$ \\
\hline Extent of benefits from elephants to mankind & $1.21 \pm 0.75$ & $1-5(1=$ none; $5=$ very beneficial $)$ \\
\hline Extent of benefits from elephants to nature & $1.52 \pm 1.17$ & $1-5(1=$ none; $5=$ very beneficial $)$ \\
\hline \multicolumn{3}{|l|}{ Tolerance } \\
\hline Tolerance of crop loss to elephants & $1.69 \pm 6.85$ & $1-6(1=$ low $6=$ high $)$ \\
\hline Tolerance of elephants visiting your village & $2.35 \pm 1.91$ & $1-6(1=$ low $; 6=$ high $)$ \\
\hline $\begin{array}{l}\text { Extent to which you would like the elephant population to } \\
\text { decrease (1), stay the same (3), or increase (5) }\end{array}$ & $2.25 \pm 1.26$ & $1-5(1=$ low; $5=$ high $)$ \\
\hline $\begin{array}{l}\text { Extent to which you would not tolerate the killing of an } \\
\text { elephant if they are common but have (1) been seen in the } \\
\text { vicinity of crops, livestock, homes, (2) raided crops, } \\
\text { injured/killed livestock, raided a home for the first time, } \\
\text { (3) repeatedly caused the problems above but never } \\
\text { harmed a person, (4) threatened a child or adult, (5) injured } \\
\text { a child or adult, (6) killed a child or adult }\end{array}$ & $6.62 \pm 0.70$ & $\begin{array}{l}1-7 \text { ( } 7=\text { complete lack of tolerance } \\
\text { for the killing of an elephant under } \\
\text { any circumstances) }\end{array}$ \\
\hline Same as above but if elephants are rare & $6.62 \pm 0.70$ & $\begin{array}{l}1-7(7=\text { complete lack of tolerance for the } \\
\text { killing of an elephant under any circumstances) }\end{array}$ \\
\hline
\end{tabular}

damage occurs within a natural order of events. Tolerant attitudes towards elephants may also stem from their association with deities (e.g. the Hindu god Ganesh; Ghosal \& Kjosavik, 2015). At our study site we often witnessed people shouting the word Maama (maternal uncle) while guarding their crops against raiding elephants, in the hope of placating the elephants. These observations were not confined to the Hindu population but also included Muslims and Christians, who do not consider the elephant to be a deity.

These socio-economic safety nets and fatalistic beliefs are likely to be more complex than we suggest; they improve resilience through the collective sum of individuals in the 
TABLE 3 Observed differences from measurement model evaluation, representing variation in reliability across the five structural equation models, each of which contains a differing selection of indicators. Model 5 is the complete model with no indicators removed, whereas Models 1-4 have selected indicators removed (see Supplementary Table 1 for a description of the indicators). For average variance extracted (AVE) a value of 0.5 or higher indicates that on average the construct explains more than half of the variance of its indicators. Composite reliability (CR) is used to determine whether the items measuring a construct are similar in their scores; the value should be in the range 0.7-0.9 but for exploratory research 0.6 is acceptable. Discriminant validity (DV) is the extent to which a construct is truly distinct from other constructs (Yes: the The Fornell-Larckner criterion was met, meaning the construct was significantly unique; No: it was not.)

\begin{tabular}{|c|c|c|c|c|c|}
\hline & Model $1^{1}$ & Model $2^{2}$ & Model $3^{3}$ & Model $4^{4}$ & Model 5 \\
\hline \multicolumn{6}{|c|}{ Exposure } \\
\hline AVE & 0.53 & 0.53 & 0.52 & 0.52 & 0.53 \\
\hline CR & 0.81 & 0.81 & 0.80 & 0.80 & 0.81 \\
\hline DV & Yes & Yes & Yes & Yes & Yes \\
\hline \multicolumn{6}{|c|}{ Intangible costs } \\
\hline AVE & 0.50 & 0.50 & 0.50 & 0.50 & 0.50 \\
\hline $\mathrm{CR}$ & 0.83 & 0.83 & 0.83 & 0.83 & 0.83 \\
\hline DV & Yes & No & Yes & Yes & Yes \\
\hline \multicolumn{6}{|c|}{ Tangible costs } \\
\hline AVE & 0.25 & 0.25 & 0.51 & & 0.25 \\
\hline $\mathrm{CR}$ & 0.57 & 0.57 & 0.55 & & 0.57 \\
\hline DV & Yes & No & No & Yes & Yes \\
\hline \multicolumn{6}{|c|}{ Intangible benefits } \\
\hline AVE & 0.35 & 0.43 & 0.44 & 0.44 & 0.35 \\
\hline $\mathrm{CR}$ & 0.72 & 0.68 & 0.68 & 0.68 & 0.72 \\
\hline DV & Yes & No & No & No & Yes \\
\hline \multicolumn{6}{|c|}{ Tolerance } \\
\hline AVE & 0.55 & 0.55 & 0.55 & 0.55 & 0.43 \\
\hline $\mathrm{CR}$ & 0.78 & 0.78 & 0.78 & 0.78 & 0.73 \\
\hline DV & Yes & No & Yes & Yes & Yes \\
\hline
\end{tabular}

${ }^{1}$ Indicators removed from Model 1: Tol_kill_(1+2) (tolerance).

${ }^{2}$ Indicators removed from Model 2: Tol_kill_( $\left.1+2\right)$ (tolerance), Ben_you (intangible benefits), Ben_com (intangible benefits).

${ }^{3}$ Indicators removed from Model 3: Tol_kill_( $\left.1+2\right)$ (tolerance), Ben_you (intangible benefits), Ben_com (intangible benefits), Mitigation_effort (tangible costs), Hours_lost_night (tangible costs), Spent_mitigation (tangible costs).

${ }^{4}$ Indicators removed from Model 4: Tol_kill_(1 +2$)$ (tolerance), Ben_you (intangible benefits), Ben_com (intangible benefits), Mitigation_effort (tangible costs), Hours_lost_night (tangible costs), Spent_mitigation (tangible costs), cost_dry (tangible costs).

community exhibiting their cultural norms. In a sense, tangible costs may not really be experienced independently by the individual but shared by the unified common culture of the community, which may explain further why direct costs were non-significant.

Intangible costs, on the other hand, were significant in driving tolerance among all respondents, similar to the South African study (Kansky et al., 2016). Commonly cited costs were fear and stress, and the loss of sleep and productivity resulting from all-night vigils to guard fields. Framed within the concept of universal human needs
TABLE 4 Path coefficients for Models 1-5, with significant pathways indicated in bold, and change in significance as a result of the removal of an indicator indicated in italics.

\begin{tabular}{|c|c|c|c|c|c|}
\hline Pathway $^{1}$ & Model 1 & Model 2 & Model 3 & Model 4 & Model \\
\hline $\mathrm{IB} \rightarrow \mathrm{TOL}$ & 0.31 & 0.34 & 0.34 & 0.34 & 0.33 \\
\hline$\rightarrow$ TOL & -0.32 & -0.32 & -0.31 & -0.31 & -0.32 \\
\hline $\mathrm{TC} \rightarrow \mathrm{TOL}$ & -0.06 & -0.06 & -0.08 & -0.08 & -0.05 \\
\hline $\mathrm{EXPO} \rightarrow \mathrm{TOL}$ & 0.11 & 0.10 & 0.11 & 0.11 & 0.09 \\
\hline $\mathrm{PME} \rightarrow \mathrm{TOL}$ & -0.03 & -0.00 & -0.04 & -0.00 & -0.02 \\
\hline $\mathrm{NME} \rightarrow \mathrm{TOL}$ & -0.08 & -0.06 & -0.07 & -0.07 & -0.09 \\
\hline $\mathrm{NME} \rightarrow \mathrm{IB}$ & -0.08 & -0.14 & -0.14 & -0.14 & -0.09 \\
\hline $\mathrm{NME} \rightarrow \mathrm{IC}$ & 0.07 & 0.07 & 0.07 & 0.07 & 0.07 \\
\hline $\mathrm{NME} \rightarrow \mathrm{TC}$ & -0.08 & -0.08 & -0.17 & -0.17 & -0.08 \\
\hline $\mathrm{PME} \rightarrow \mathrm{IB}$ & -0.03 & -0.05 & -0.05 & -0.05 & -0.03 \\
\hline $\mathrm{PME} \rightarrow \mathrm{IC}$ & 0.02 & 0.02 & 0.02 & 0.02 & 0.01 \\
\hline $\mathrm{PME} \rightarrow \mathrm{TC}$ & 0.11 & 0.11 & 0.02 & -0.02 & 0.11 \\
\hline $\mathrm{EXPO} \rightarrow \mathrm{IB}$ & 0.13 & 0.11 & 0.17 & 0.17 & 0.13 \\
\hline $\mathrm{EXPO} \rightarrow \mathrm{IC}$ & -0.06 & -0.06 & -0.08 & -0.08 & -0.06 \\
\hline $\mathrm{EXPO} \rightarrow \mathrm{TC}$ & 0.40 & 0.40 & 0.40 & 0.40 & 0.40 \\
\hline $\mathrm{EXPO} \rightarrow \mathrm{NME}$ & 0.20 & 0.20 & 0.20 & 0.20 & 0.20 \\
\hline $\mathrm{EXPO} \rightarrow \mathrm{PME}$ & 0.16 & 0.16 & 0.16 & 0.16 & 0.16 \\
\hline
\end{tabular}

${ }^{1} \mathrm{IB}$, intangible benefits; TOL, tolerance; IC, intangible costs; TC, tangible costs; EXPO, exposure; PME, positive meaningful events; NME, negative meaningful events.

(Tay \& Diener, 2011), these can be understood as unmet needs, such as lack of autonomy, lack of safety, and opportunity costs (e.g. time spent guarding against elephants could otherwise have been spent socializing). For residents of Sherpur we suggest a reduction in intangible costs could be achieved by employing specialized teams to guard fields, releasing farmers to focus on farming and to ensure adequate sleep, as well as creating jobs for unemployed youth. More research on intangible costs will be necessary to design initiatives that address the whole spectrum of costs endured by communities living with wildlife (Ogra, 2008; Barua et al., 2013; Pooley et al., 2017), to inform arguments that will persuade policy makers/donors to support alleviating these costs. Alongside these intangible costs, intangible benefits were found to be equally significant for tolerance. Where intangible benefits are recognized, they lead to increased tolerance, suggesting that fostering the positive ontological and underlying relationships that people in Sherpur already have with elephants and increasing people's awareness of intangible benefits would be valid as a management mechanism.

We have explained how costs and benefits drive tolerance, which is the main focus of our research; however, it is also necessary to expound briefly on what initially affects the costs and benefits communities in Sherpur perceive. Although increasing exposure to elephants understandably resulted in increased tangible costs (Fig. 3), reducing exposure will not necessarily increase tolerance, as tangible costs are not a significant driver of tolerance. There was also a lack of significance between exposure and intangible costs or benefits, 
TABLE 5 Coefficient of determination (unadjusted $R^{2}$ ) for all models.

\begin{tabular}{|c|c|c|c|c|c|}
\hline & Model 1 & Model 2 & Model 3 & Model 4 & Model 5 \\
\hline Intangible benefits & 0.023 & 0.033 & 0.036 & 0.036 & 0.023 \\
\hline Intangible costs & 0.006 & 0.006 & 0.008 & 0.008 & 0.006 \\
\hline Tangible costs & 0.178 & 0.179 & 0.166 & 0.166 & 0.178 \\
\hline Negative meaningful events & 0.041 & 0.041 & 0.041 & 0.041 & 0.041 \\
\hline Positive meaningful events & 0.025 & 0.025 & 0.025 & 0.025 & 0.025 \\
\hline Tolerance & 0.326 & 0.339 & 0.341 & 0.341 & 0.331 \\
\hline
\end{tabular}

possibly because of the highly stochastic and dangerous nature of elephant visits (Davies et al., 2011), where one visit may be sufficient to shape perceptions permanently. Hence, interventions seeking to foster direct human-elephant interactions are unlikely to improve tolerance.

Similarly, negative meaningful events were significant in driving tangible costs. However, although positive meaningful events are predicted to increase intangible benefits, as was found in South Africa (Kansky et al., 2016), this did not hold true in Bangladesh. This may stem from cultural beliefs in which elephants are respected/anthropomorphized (e.g. people identify with mourning behaviours expressed by elephants following a death in a herd; Barua et al., 2013), and thus perceived benefits are already fixed through deep-seated cultural conditioning processes rather than positive interactions with elephants. Overall, the costs and benefits in our study may have been driven by indicators we did not measure, and understanding what affects costs and benefits may be improved by employing the inner model variables (e.g. empathy and anthropomorphism) of the wildlife tolerance model (Supplementary Material 1).

In conclusion, the non-significance of tangible costs and the significance of intangible costs in driving tolerance suggest that in this case monetary compensation schemes may not be the most appropriate mechanism for increasing tolerance. This recommendation holds true as long as there is not a monetary threshold above which communities will not tolerate further monetary costs. Undoubtedly there will be occasions when monetary compensation is required but we should endeavour to avoid identifying drivers of tolerance and the costs communities face using only our intuition.

As conservationists we must advocate the use of robust science in achieving conservation goals whilst maintaining a sensitivity that balances conservation equally as a human discourse (Pooley et al., 2017). Presented with this challenge, research on human-wildlife coexistence is usually designed for specific contexts using methodologies and variables appropriate to individual cases, but this prevents useful comparisons across contexts (Kansky et al., 2016). The wildlife tolerance model provides a single model for repeated testing, which can promote development of testable theory and facilitate the identification of statistically robust drivers of tolerance. Such repeated testing is not common in conservation (Fazey et al., 2005), to the detriment of conservation science and practice. If repeated testing is conducted and tangible costs are found to be non-significant across a broad range of contexts, the implications could include redirection of funding (Santangeli \& Sutherland, 2017) and reprioritization of our efforts to address the costs communities truly face.

Acknowledgements We thank WildTeam Bangladesh for supporting this research, Md Anwarul Islam for his invaluable hosting, Dipongkor Roy for his time in the field, two anonymous reviewers for their insightful comments, Jocelyne Sze for her contributions, and all the respondents for their time and generous hospitality.

Author contributions Conception of research: RK, AK; design and implementation of fieldwork: OS, AP; data analysis: MK; writing: OS, RK, AK.

\section{Conflicts of interest None.}

Ethical standards The research proposal was approved by the ethics committees of the Department of Life Sciences, Imperial College London, and the Department of Zoology, Dhaka University, and conforms to the British Sociological Association's ethical standards.

\section{References}

Agarwala, M., Kumar, S., Treves, A. \& Naughton-Treves, L. (2010) Paying for wolves in Solapur, India and Wisconsin, USA: comparing compensation rules and practice to understand the goals and politics of wolf conservation. Biological Conservation, 143, 2945-2955.

Aziz, A., Shamsuddoha, A., Maniruddin, M., Morshed, H., SARKER, R. \& Islam, M. (2016) Elephants, border fences and human-elephant conflict in northern Bangladesh: implications for bilateral collaboration towards elephant conservation. Gajah, 45, 12-19.

B A bire, E. (2015) The Practice of Social Research. 13th edition. Cengage Learning, Boston, USA.

Barua, M., Bhagwat, S.A. \& Jadhav, S. (2013) The hidden dimensions of human-wildlife conflict: health impacts, opportunity and transaction costs. Biological Conservation, 157, 309-316.

Bulte, E. \& Rondeau, D. (2005) Research and management viewpoint: why compensating wildlife damages may be bad for conservation. Journal of Wildlife Management, 69, 14-19.

Bulte, E. \& Rondeau, D. (2007) Compensation for wildlife damages: habitat conversion, species preservation and local welfare. 
Journal of Environmental Economics and Management, 54, 311-322.

Davies, T.E., Wilson, S., Hazarika, N., Chakrabarty, J., Das, D., Hodgson, D.J. \& Zimmermann, A. (2011) Effectiveness of intervention methods against crop-raiding elephants. Conservation Letters, 4, 346-354.

DeMotts, R. \& Hoon, P. (2012) Whose elephants? Conserving, compensating, and competing in northern Botswana. Society \& Natural Resources, 25, 837-851.

Dickman, A.J. (2010) Complexities of conflict: the importance of considering social factors for effectively resolving human-wildlife conflict. Animal Conservation, 13, 458-466.

Dickman, A.J. \& Hazzah, L. (2016) Money, myths and man-eaters: complexities of human-wildlife conflict. Problematic Wildlife (ed. F.M. Angelici), pp. 339-356. Springer, Cham, Switzerland.

Di Marco, M., Boitani, L., Mallon, D., Hoffmann, M., Iacucci, A., Meijandi, E. et al. (2014) A retrospective evaluation of the global decline of carnivores and ungulates. Conservation Biology, 28, 1109-1118.

Fazey, I., Fazey, J.A. \& Fazey, D.M.A. (2005) Learning more effectively from experience. Ecology and Society, 10, 4.

GHOSAL, S. \& KJOSAVIK, D.J. (2015) Living with leopards: negotiating morality and modernity in western India. Society \& Natural Resources, 28, 1092-1107.

Gogol, M. (2018) Emotional coping among communities affected by wildlife-caused damage in north-east India: opportunities for building tolerance and improving conservation outcomes. Oryx, 52, 214-219.

Hair, Jr, J.F., Hult, G.T.M., Ringle, C. \& Sarstedt, M. (2016) A Primer on Partial Least Squares Structural Equation Modeling (PLS-SEM). Sage Publications, Thousand Oaks, USA.

Inskip, C., Carter, N., Riley, S., Roberts, T. \& MacMillan, D. (2016) Toward human-carnivore coexistence: understanding tolerance for tigers in Bangladesh. PLOS ONE, 11, eo145913.

Islam, M., Khan, M.M., Kabir, M., Chowdhury, M., Feeroz, M. \& BEGUM, S. (1999) Man-elephant interactions in Bangladesh in 1997. Bangladesh Journal of Life Science, 11, 31-36.

Islam, M.A., Mohsanin, S., Chowdhury, G.W., Choudhury, S.U., Aziz, M.A., Uddin, M. et al. (2011) Current status of Asian elephants in Bangladesh. Gajah, 35, 21-24.

KAnSKY, R., KidD, M. \& KNight, A.T. (2016) A wildlife tolerance model and case study for understanding human wildlife conflicts. Biological Conservation, 201, 137-145.

Lowry, P.B. \& Gaskin, J. (2014) Partial least squares (PLS) structural equation modeling (SEM) for building and testing behavioral causal theory: when to choose it and how to use it. IEEE Transactions on Professional Communication, 57, 123-146.

Marino, A., Braschi, C., Ricci, S., Salvatori, V. \& Ciucci, P. (2016) Ex post and insurance-based compensation fail to increase tolerance for wolves in semi-agricultural landscapes of central Italy. European Journal of Wildlife Research, 62, 227-240.

Motaleb, M. \& Ahmed, M. (2016) Status of Asian Elephants in Bangladesh. IUCN, Dhaka, Bangladesh.
Muradian, R., Arsel, M., Pellegrini, L., Adaman, F., Agullar, B., Agarwal, B. et al. (2013) Payments for ecosystem services and the fatal attraction of win-win solutions. Conservation Letters, 6 , 274-279.

Naughton-Treves, L., Grossberg, R. \& Treves, A. (2003) Paying for tolerance: rural citizens' attitudes toward wolf depredation and compensation. Conservation Biology, 17, 1500-1511.

OGRA, M.V. (2008) Human-wildlife conflict and gender in protected area borderlands: a case study of costs, perceptions, and vulnerabilities from Uttarakhand (Uttaranchal), India. Geoforum, 39, 1408-1422.

Peterson, M.N., Peterson, M.J., Peterson, T.R. \& Leong, K. (2013) Why transforming biodiversity conservation conflict is essential and how to begin. Pacific Conservation Biology, 19, 94-103.

PING, R. (2007) Salesperson-employer relationships: salesperson responses to relationship problems and their antecedents. Journal of Personal Selling and Sales Management, 27, 39-57.

Pooley, S., Barua, M., Beinart, W., Dickman, A., Holmes, G., LORIMER, J. et al. (2017) An interdisciplinary review of current and future approaches to improving human-predator relations. Conservation Biology, 31, 513-523.

Ravenelle, J. \& Nyhus, P.J. (2017) Global patterns and trends in human-wildlife conflict compensation. Conservation Biology, 31, $1247-1256$.

Reinartz, W., Haenlein, M. \& Henseler, J. (2009) An empirical comparison of the efficacy of covariance-based and variancebased SEM. International Journal of Research in Marketing, 26, 332-344.

Ringle, C.M., Wende, S. \& Becker, J.-M. (2015) SmartPLS 3. Http://www.smartpls.com [accessed 12 December 2018].

Santangeli, A. \& Sutherland, W.J. (2017) The financial return from measuring impact. Conservation Letters, 10, 354-360.

Sarker, A.H.M.R. \& Røskaft, E. (2014) Perceptions of farmers in Bangladesh to Asian elephants (Elephas maximus). Environment and Natural Resources Research, 4, 23-38.

Schwerdtner, K. \& Gruber, B. (2007) A conceptual framework for damage compensation schemes. Biological Conservation, 134, 354-360.

Sommerville, M., Jones, J.P.G., Rahajaharison, M. \& Milner-Gulland, E.J. (2010) The role of fairness and benefit distribution in community-based Payment for Environmental Services interventions: a case study from Menabe, Madagascar. Ecological Economics, 69, 1262-1271.

TAY, L. \& DiEnER, E. (2011) Needs and subjective well-being around the world. Journal of Personality and Social Psychology, 101, 354-365.

Treves, A. \& Bruskotter, J. (2014) Tolerance for predatory wildlife. Science, 344, 476-477.

Treves, A., Wallace, R.B. \& White, S. (2009) Participatory planning of interventions to mitigate human-wildlife conflicts. Conservation Biology, 23, 1577-1587.

WonG, K.K.-K. (2013) Partial least squares structural equation modeling (PLS-SEM) techniques using SmartPLS. Marketing Bulletin, 24, 1-32. 